\title{
GOD AND THE ARGUMENT FROM CONSCIOUSNESS: A RESPONSE TO LIM
}

\author{
J. P. MORELAND \\ Biola University
}

Recently, Daniel Lim has published a thoughtful critique of one form of my argument for the existence of God from consciousness (hereafter, AC).1 After stating his presentation of the relevant contours of my argument, I shall present the main components of his critique, followed by my response. Since one purpose of my publications of AC has been to foster discussion about a neglected argument for God's existence, I am thankful to Lim for his interesting article and the chance to further the discussion.

\section{LIM'S PRESENTATION OF MY DEDUCTIVE VERSION OF AC}

Lim claims that my presentation of AC is essentially a God-of-the-gaps argument and offers this version of it:

(1) Genuinely non-physical mental states exist.

(2) There is an explanation for the existence of mental states.

(3) Personal explanation is different from natural scientific explanation.

(4) The explanation for the existence of mental states is either a personal or natural scientific explanation.

(5) The explanation is not a natural scientific one.

${ }^{1}$ Daniel Lim, “Zombies, Epiphenomenalism, and Personal Explanation: A Tension in Moreland's Argument from Consciousness", European Journal for Philosophy of Religion 3/2 (Autumn, 2011), 439-450. 
(6) Therefore, the explanation is a personal one.

(7) If the explanation is personal, then it is theistic.

(8) Therefore, the explanation is theistic.

Lim focuses on four reasons I have offered for (5), and spends the entirety of his subsequent critique on an alleged tension between (b) and (c) below. Those reasons are (a) the uniformity of nature, (b) the contingency of the mind-body correlation, (c) the rejection of epiphenomenalism based on causal closure, and (d) the inadequacy of evolutionary explanations.

\section{LIM'S CRITIQUE OF AC}

Lim claims that the contingency of the mental/physical connection (which he calls "Contingency" with a capital "C") is crucial for my argument because it makes room for a personal explanation of that connection. Further and in general, contingency is required for a personal explanation since the offering of a theistic personal explanation seems to presuppose the contingency of the phenomenon to be explained. Applied to Contingency, in this way the explanans (God's free choice to make the connection the way it is) comports well with the explanandum (Contingency). Thus, Contingency is a necessary condition for a successful AC.

In addition, according to Lim, the falsity of epiphenomenalism, given a robust version of naturalism, is important for my defence of premise (5) of AC (the explanation of the existence of mental entities is not a natural scientific one). Briefly, Lim says my argument is that naturalism implies the causal closure of the physical, closure implies epiphenomenalism for irreducible mental states, epiphenomenalism is false, so naturalism is false. Thus, there is no naturalistic explanation for irreducible mental states.

At this point in his critique, Lim claims that there is now a tension in my defence of AC: My rejection of epiphenomenalism is at odds with my commitment to Contingency because Contingency entails epiphenomenalism as as expressed in $\mathrm{C} 4$ :

\section{C4: Contingency $\rightarrow$ Epiphenomenalism}

Now, prima facie, C4 seems implausible. Indeed, numerous thinkers in the history of philosophy, not to mention most laypeople throughout the world, both now and throughout history, have accepted Contingency and a denial of epiphenomenalism. So $\mathrm{C} 4$ needs a pretty robust defence 
and Lim seeks to provide one. First, he invites us to consider the "standard" ways of characterizing zombies (e.g., something physically identical to me but bereft of mental states) in a world physically identical to the actual world. In such a world, my zombie twin is physically, functionally and behaviourally identical to me in the actual world. Let $\mathrm{PW}_{\mathrm{Z}}$ and $\mathrm{PW}_{\circledast}$ stand for a zombie world and the actual world, respectively. The only difference between these worlds is that metal states obtain in the latter and not the former. But, then, it becomes clear, says Lim, that the presence or absence of mental states makes no causal contribution to $\mathrm{PW}_{\odot}$, and this is why $\mathrm{C} 4$ is true. So in my version of AC, either I accept Contingency or I reject it. If I reject it, there is no need for a personal theistic explanation of the correlations, and if I accept it, I must accept an implausible view which, in fact, I reject, viz., epiphenomenalism.

However, Lim suggests I have a way out and that would be to reject C4. Epiphenomenalism can be avoided if the zombie world $\mathrm{PW}_{\mathrm{Z}}$ is missing something the actual world $\mathrm{PW}_{@}$ has, namely, the laws of nature (which are different in the two worlds). Mental states could be causally efficacious in $\mathrm{PW}_{\Theta}$ as long as $\mathrm{PW}_{\mathrm{Z}}$ is a counter-nomological world, i.e., one with different laws of nature. This solution is available if we accept Categoricalism (all properties are categorical, i.e., they don't confer any causal powers/dispositions on their bearers), and depict the laws of nature as metaphysically contingent relations among categorical properties such that these laws contingently confer causality "from the outside" on their relata. ${ }^{2}$ Thus, in $\mathrm{PW}_{\Theta}$ there are contingent mental/ physical causal laws that vouchsafe the causal efficacy of the mental that do not obtain in $\mathrm{PW}_{\mathrm{Z}}$.

As an illustration, Lim invites us to suppose that in $\mathrm{PW}_{\Theta}$, my mental states and brain states together bring about my shouting "ouch" (i.e., $(\mathrm{M} \& \mathrm{P}) \rightarrow \mathrm{E})$. Now, $\mathrm{E}$ won't obtain in $\mathrm{PW}_{\mathrm{Z}}$ because $\mathrm{M}$ is absent. But then, $\mathrm{PW}_{\mathrm{Z}}$ does not satisfy the "standard" analysis of zombies embedded in a physically indistinguishable world. To get such a world, we need $\mathrm{PW}_{\mathrm{Z} \text {-LAW }}$ in which the laws of nature differ from those in $\mathrm{PW}_{\Theta}$. In $\mathrm{PW}_{\Theta}$, there is a law such as $(\mathrm{M} \& \mathrm{P}) \rightarrow \mathrm{E}$. But in $\mathrm{PW}_{\mathrm{Z}-\mathrm{LAW}}$, there is a different law that guarantees that $\mathrm{P}$ alone brings about $\mathrm{E}$. In this case we have contingency with respect to two physically indistinguishable worlds $\mathrm{PW}_{\Theta}$ and $\mathrm{PW}_{\mathrm{Z}-\mathrm{LAW}}$ and mental efficacy is preserved in $\mathrm{PW}_{\Theta}$.

${ }^{2}$ For a helpful discussion of Categoricalism and Dispositional Essentialism, see Alexander Bird, "Laws and Essences", Ratio 18 (2005), 437-461. 
Unfortunately, this is not a satisfactory way out for the defender of $\mathrm{AC}$, and Lim presents two main arguments against it. First, he claims that it is unclear that we can preserve the physical identity of some brain state P from $\mathrm{PW}_{\Theta}$ to $\mathrm{PW}_{\mathrm{Z} \text {-LAW }}$ because some strong version of Dispositional Essentialism is superior to Categoricalism regarding properties and their identity conditions, the former can and the latter cannot adequately ground P's physical identity between the two worlds, yet it is the inferior Categoricalism that funds this way out for the defender of AC. Let us characterize Strong Dispositional Essentialism (SDE) in this way:

SDE: Some properties are essentially dispositional, those dispositions ground and are metaphysically necessarily connected to the laws into which those properties figure, and two properties Q and R are identical if and only if, necessarily, $\mathrm{Q}$ and $\mathrm{R}$ share all and only the same dispositions.

According to SDE, laws of nature are not contingently related to properties. Rather, a law of nature involving a property Q is grounded in and metaphysically necessarily related to Q's dispositions such that Q cannot exist in two possible worlds in association with two different related laws of nature. So brain state $P$ that essentially instantiates some property $\mathrm{Q}$ does not preserve its identity between $\mathrm{PW}_{\Theta}$ and $\mathrm{PW}_{\mathrm{Z}-\mathrm{LAW}}{ }^{3}$

Second, Lim claims that $\mathrm{PW}_{\text {Z-LAW }}$ is a red herring in any case, and it is not really relevant to the problem of epiphenomenalism. Why? Because if $\mathrm{PW}_{\mathrm{Z}}$ is really possible, a world identical to $\mathrm{PW}_{\Theta}$ in every way, this alone establishes epiphenomenalism.

In sum, I have presented a precis of Lim's critique of my version of AC, especially my defence of premise (5). I now turn to the task of providing a reply to Lim.

\section{MY REPLY TO LIM'S CRITIQUE}

In this section, I shall present two initial responses to Lim, followed by a reply to his main contention about Contingency and epiphenomenalism.

${ }^{3}$ Lim also raises an epistemological worry, namely, if physical properties and their instantiations can exist throughout a range of possible worlds with various causal profiles for those properties and instantiations, not only would this be unparsimonious, but it would generate vast ranges of empirically equivalent possible worlds with radically different underlying property-ontologies. Now besides the fact that opponents of realism in science would be happy with this latter result, I shall not interact with this criticism further because, as we shall see below, I am not a Categoricalist. 


\section{God-of-the-Gaps and Necessitation}

Lim claims that my version of AC is a God-of-the-gaps argument, but he is simply wrong in this. ${ }^{4}$ A gaps argument is one in which a scientific explanation of some phenomenon is possible in principle, but not yet provided, and into that explanatory gap a rival theistic explanation is proffered. But my defence of premise (5) of AC, especially (b) contingency, (c), epiphenomenalism, and (d) the inadequacy of evolutionary explanations, provide in-principle objections to the very possibility of scientific explanation. Whether successful or not, they seek to place a limit on scientific explanation regarding the existence of mental entities, to claim that they must, therefore, be taken as brute facts or explained theistically, and to provide grounds for preferring a theistic explanation. Thus, my argument is not a gaps-type presentation. This is not a minor point. In the current intellectual climate, there is widespread loathing for gaps arguments, and it would be damaging to AC if one were to think, erroneously, that it is a gaps argument.

Second, Lim's claim that a defender of AC needs Contingency (the contingency of the mental/physical connection) is mistaken. Put briefly, the defender of AC needs contingency but not Contingency. The existence of the mental must, in some way or another, be a contingent fact, but its emergence from the physical need not be. Consider the following possibility. Suppose that mental states emergently supervened upon relevant brains states with metaphysical necessity. In this case, Contingency would be violated. However, a defender of AC could ask why those contingent subvenient brain states obtained as opposed to alternative states. If the relevant brain states were the result of a causal chain of events leading back to the Big Bang, the AC advocate could ask why this chain as opposed to an alternative one obtained in the actual world. And a personal theistic explanation would be available (e.g., the properties of consciousness are exemplified by the fundamental being in theism; thus, they exist and are available for subsequent exemplification in the history of the cosmos; good persons - divine or otherwise - love to

${ }^{4}$ Elsewhere, I have evaluated God-of-the-gaps arguments in the context of debates about whether or not methodological naturalism is a necessary condition for the practice of science. See J. P. Moreland, “Theistic Science and Methodological Naturalism” in The Creation Hypothesis, edited by J. P. Moreland (Downers Grove, Illinois: InterVarsity Press, 1994), pp. 41-66. 
bring other persons into existence and have relationships with them, so God would have a good reason to being about those subvenient states).

Now, I accept Contingency so this way out is not one I can embrace. But I do embrace the contingency of physical states that are causally relevant for the appearance of mental states, so in my case, both sorts of AC are available. And in any case, an AC advocate who denied Contingency could still advance an AC type argument as we have seen, and this fact is sufficient to defeat Lim's argument. Still, since I accept Contingency, I have to face the tension between it and epiphenomenalism which I reject. And it is to this issue we now turn.

\section{Contingency and Epiphenomenalism: Problems with $\mathrm{C4}$}

I have two basic responses to Lim' employment of C4 (Contingency $\rightarrow$ Epiphenomenalism) to expose a tension in my arguments for AC's premise (5). The first one is epistemological. As I mentioned earlier, the vast majority of people throughout history have accepted Contingency and denied epiphenomenalism, including a very impressive number of philosophers down through the ages. Belief in some sort of disembodied life after death is ubiquitous, people have no problem with the (metaphysical) possibility of Near Death experiences, zombies frequently populate science fiction writing, and when presented with an explanation of inverted qualia thought experiments, lay people clearly believe they could, indeed, happen. And almost no one accepts epiphenomenalism. If there is any place where the intuitions of folk ontology should count, and I and many others think they should, this is it.

But the same thing cannot be said for the highly abstract debates about identity conditions for properties, the proper analysis of laws of nature, how the two relate to one another, and so forth. One could take oneself to have a principled, justified position on these topics, but one's underlying intuitions would be far weaker than those of folk ontology supporting Contingency and a denial of epiphenomenalism. Given this epistemic disparity, it seems to me that one could be justified in accepting Contingency and denying epiphenomenalism without having any reply to $\mathrm{C} 4$. Or one could reject $\mathrm{C} 4$ by opting for, say, a Humean regularity view of laws, or Armstrong's nomic necessitation view, precisely because they preserve these folk ontological intuitions, even if, considered in themselves, one preferred Strong Dispositional Essentialism to these 
alternatives. ${ }^{5}$ It seems to me that this is the epistemology of the situation, and Lim does not take it into account. Thus, Lim's statement "that AC in its present form cannot be used to persuade naturalistic dualists" (p. 449) is unwarranted and premature.

So much for my epistemological observation. My second reply to Lim takes as a starting point his concession that epiphenomenalism can be avoided as long as the zombie world $\mathrm{PW}_{\mathrm{Z}}$ is in some relevant way different from the actual world $\mathrm{PW}_{\Theta}$. In a related comment Timothy O'Connor has observed that if an emergent property is depicted in such a way as to be contingently linked to the base properties causing it to emerge, then apart from an appeal to God's contingent choice that things be so, and to God's stable intention that they continue to be so, there will be no explanation for the link itself or its constancy. ${ }^{6}$ Lim's mistake is his suggestion that a Categoricalist depiction of contingent laws of nature is the only way out. But this is mistaken. There is an alternative for an AC advocate that rejects Categoricalism, embraces a mitigated form of Dispositional Essentialism, and provides the resources to defeat C4. Let me explain.

Consider this form of Mitigated Dispositional Essentialism (MDE):

MDE: Some properties, e.g., $\mathrm{P}$, are essentially dispositional in that they have dispositions, e.g., $\mathrm{D}_{\mathrm{I}}-\mathrm{D}_{\mathrm{N}}$, and these dispositions, along with the intrinsic categorical nature of, e.g., $P$, together provide the identity conditions for $\mathrm{P}$. In addition, properties like $\mathrm{P}$ can have accidental dispositions $\mathrm{D}_{\mathrm{O}}-\mathrm{D}_{\mathrm{S}}$ that are not essential to $\mathrm{P}$.

Among other things, MDE entails that not all the dispositions of a given property are essential to its identity. Thus, a property - or a state essentially characterized by a property - can retain its identity though accidental change. Given MDE, my response to Lim amounts to the claim that the difference between $\mathrm{PW}_{\Theta}$ and $\mathrm{PW}_{\mathrm{Z}}$ resides in a difference in accidental dispositions. MDE provides a way for properties and their associated states to retain identity across possible worlds. And by providing an account in which the actual and a zombie world are duplicates physically but not duplicates simpliciter, MDE provides the resources for defeating $\mathrm{C} 4$ while granting the existence of $\mathrm{PW}_{\mathrm{Z}}$. Thus,

${ }^{5}$ For a recent metaphysical analysis of options on these matters, see E. J. Lowe, The Four-Category Ontology (Oxford: Clarendon Press, 2006), pp. 121-173.

${ }^{6}$ Timothy O'Connor, Persons and Causes (New York: Oxford University Press, 2000), pp. 70-71. 
MDE preserves Contingency and a rejection of epiphemonenalism, and at the same time provides answers to Lim's two criticisms. Now consider the following two scenarios:

Scenario One: Let us set aside the "standard" account of zombies as expressed in $\mathrm{PW}_{\mathrm{Z}}$, in favour of a "non-standard account expressed in $\mathrm{PW}_{\mathrm{NSZ}}$ (a non-standard zombie world). Such a world is bereft of mental states and their causal effects (e.g., there is no shouting of "ouch"). Such a world seems possible, and it is all a defender of AC needs. After all, the point of zombies in AC is to illustrate the contingency of the existence of the mental, and that is captured in $\mathrm{PW}_{\mathrm{NSz}}$. Now suppose that in the actual world, there is a disposition of a subvenient base physical property that, when triggered, actualizes the mental property. What are we to say about this disposition in $\mathrm{PW}_{\mathrm{NSz}}$ ? It seems that there are two ways to go. First, one can say that in the actual world, this disposition was an accidental property superadded and sustained by God, but is missing in $\mathrm{PW}_{\mathrm{NSZ}}$. Since this disposition plays no role in physical theory nor is it strictly a physical disposition capable of complete description in ideal physical terms (it's description involves reference to a mental entity), then the nonstandard world is physically identical to the actual world, but absent the relevant metaphysical (non-physical) disposition. Or one can say that in $\mathrm{PW}_{\mathrm{NSZ}}$, the disposition to produce a mental state is present, but that God has superadded and sustains an overriding blocking disposition. Either way, Contingency and a rejection of epiphenomenalism are preserved, $\mathrm{PW}_{\mathrm{NsZ}}$ is in place, and the relevant property identities are retained across the two worlds.

Scenario Two: Here we adopt the "standard" account of zombies and consider $\mathrm{PW}_{\mathrm{Z}}$ in which the brain state $\mathrm{P}$ causes $\mathrm{E}$ (a shouting of "ouch"). In the actual world, there is a set of non-physical, contingent dispositions that are relevant to the existence of the mental and its causal powers that are absent in the zombie world. What are those dispositions? I'm not sure, and I am not sure a detailed account of them is required for my argument. But I can speculate. Suppose in $\mathrm{PW}_{\odot}$ there are six dispositions absent from $\mathrm{PW}_{\mathrm{Z}}{ }^{7}$ the mental disposition $\mathrm{MD}$ that, when actualized, gives rise to $\mathrm{M}$, a disposition of $\mathrm{MD}$ that gives $\mathrm{MD}$ the potential to receive causal power from the subvenient base, a disposition of that

${ }^{7}$ In a related project with very different aims, Colin McGinn postulates three dispositional properties and not six. See his The Mysterious Flame: Conscious Minds in a Material World (New York: Basic Books, 1999). 
subvenient base to interact with MD's disposition to broker the causal activity that actualizes MD, a disposition of $\mathrm{M}$ to act causally on matter (e.g., to produce the bodily motions involved in shouting "ouch"), the various bodily dispositions to receive mental causal activity, and an overriding/blocking disposition that prevents B from causing E without M's involvement. In this scenario, we have Contingency, a rejection of epiphenomenalism, and an intact $\mathrm{PW}_{\mathrm{Z}}$.

Lim could reject my two scenarios on the grounds that their associated zombie worlds are not adequate. In one place, Lim describes the adequacy relationship between two worlds relevant to our topic as "being identical in every way" (p. 448), and my two zombie worlds fail this criterion when compared to the actual world. But this characterization substantially begs the question against the defender of AC. More importantly, it is equivocal to what Lim says elsewhere when he describes the adequacy relationship as requiring the two relevant worlds to be physically identical, including physical events. This, I take it, is Lim's actual view. If I am right about this, then my two zombie worlds satisfy this adequacy condition compared to the actual world, and my scenarios defeat Lim's critique.

In summary, I am grateful to Lim for his thoughtful critique of my argument for God from the existence of irreducible, uneliminable mental states. But, as I have tried to show, I do not believe his critique succeeds. ${ }^{8}$

\footnotetext{
${ }^{8}$ Lim concludes his critique by claiming that a solution relevantly similar to mine requires a rejection of closure, but since the purpose of $\mathrm{AC}$ is to persuade naturalistic property dualists, and since rejecting closure is unavailable to the naturalist, it would be dialectically useless to undermine $\mathrm{C} 4$ by rejecting closure. But Lim's remarks misconstrue the use of closure in defence of (5), viz., as a reductio against property dualist naturalists. The argument is that, given the most plausible version of naturalism, a natural scientific explanation of consciousness would entail closure, closure entails epiphenomenalism, epiphenomenalism is false, and so is closure and a natural scientific explanation of consciousness. If the falsity of C4 entails a denial of epiphenomenalism, so much the better for my defence of (5).
} 